\title{
Antibacterial Activity of Synthesized Silver Nanoparticles from Tinospora cordifolia against Multi Drug Resistant Strains of Pseudomonas aeruginosa Isolated from Burn Patients
}

\author{
Khushboo Singh', Manju Panghal', Sangeeta Kadyan¹, Uma Chaudhary ${ }^{2}$ and Jaya Parkash Yadav ${ }^{1 *}$ \\ ${ }^{1}$ Department of Genetics, M.D. University, Rohtak-124001, Haryana, India
}

${ }^{2}$ Department of Microbiology, Post Graduate Institute of Medical Sciences Rohtak-124001, Haryana, India

\begin{abstract}
In the present study, antibacterial activity of silver nanoparticles synthesized from stem of Tinospora cordifolia were analysed against multidrug-resistant strains of Pseudomonas aeruginosa isolated from burn patients. As Pseudomonas aeruginosa is a scourge of hospital burn units and its emergence as multidrug-resistant strains is a major problem in the control of nosocomial infections. Therefore, we tried to establish a combination of medicinal values of Tinospora cordifolia and nanotechnology possibly with the field of medicine for the development of antibacterial agents against these MDR strains.The synthesized silver nanoparticles were characterized by UV-visible spectroscopy, Energy Dispersive Spectroscopy and Fourier Transform Infrared Spectroscopy. Transmission Electron Microscopy and X-Ray Diffraction have revealed the size of silver nanoparticles $9 \pm 36 \mathrm{~nm}$ and $12.49 \mathrm{~nm}$ respectively. Further antibacterial activity of silver nanoparticles prepared from Tinospora cordifolia against multidrug resistant strains was determined by agar well diffusion assay and Minimum Inhibitory Concentration (MIC) was estimated by qualitative experimentation by resazurin based micro broth dilution method. All experiments were done in triplicate. The silver nanoparticles of stem of Tinospora cordifolia showed the zone of inhibition ranges from $10 \pm 0.58$ to $21 \pm 0.25 \mathrm{~mm}$. The MIC of AgNPs from stem extract was found to be 6.25 to $200 \mu \mathrm{g} / \mathrm{ml}$ against Pseudomonas aeruginosa strains. Silver nanoparticles from Tinospora cordifolia possess very good antibacterial activity which makes them a potent source of antibacterial agent.
\end{abstract}

Keywords: Tinospora cordifolia; Silver nanoparticles; Burn patients; MDR; Antibacterial

\section{Introduction}

Pseudomonas aeruginosa is an opportunistic pathogen capable of causing nosocomial infections. Patients with burns are at extraordinary risk of acquiring $P$. aeruginosa infection of the burn wound with subsequent septicaemia and death because burn injury disrupts both the normal skin barrier and many of the systemic host defence mechanisms, which makes skin susceptible to microbial colonization resulting in development of burn wound sepsis [1]. Also P.aeruginosa is a scourge of hospital burn units [2]. This is also justified by various studies $[3,4]$. P. aeruginosa is naturally resistant to a significant number of antimicrobials and this resistance of $P$. aeruginosa to commonly used therapeutic agents has increased in recent years [5]. In case of burn patients, the burned skin remains vulnerable to invasive microbial infections of all kinds until complete epithelial repair has occurred. Microbial drug resistant is emerged as a major problem in health care industry as microbes involve in the change of their metabolism and genetic structure to acquire resistant against the drugs used in the treatment of infectious disease. MDR can be defined as resistance to at least four classes of antibiotics used during treatment of these infections. Emergence of MDR strains is often may due to selective pressure of antimicrobial therapy [5].

These drug resistant pathogens are more pathogenic with high mortality rate than that of wild strain. To overcome microbial drug resistant, scientists are looking forward for the development of alternative and novel drugs. Nanotechnology is expected to open some new aspects to fight and prevent diseases using atomic scale tailoring of materials [6]. Nanotechnology is currently employed as a tool to explore the darkest avenues of medical sciences because silver nanoparticles have been well known for its strong inhibitory and bactericidal effects and can effectively used for the treatment of various infectious diseases
[7]. Therefore antimicrobial silver is now used extensively to combat organisms in wounds and burns. It works because pathogens cannot mutate to avoid the antimicrobial effect of silver. The importance of silver ions has been also found in the treatment of burn wound by various researchers who studied the antimicrobial properties of silver nanoparticles against virulent pathogens. The effect of the nanoparticles was found to be significantly more pronounced on MDR strains [6].

In the way of nanotechnology, many researchers demonstrated the green synthesis of silver nanoparticles including bacteria, actinomycetes, fungi and plants. The plant materials have been successfully used for silver nanoparticles synthesis, due to their potential medicinal property, huge availability, faster rate of synthesis $[8,9]$. Tinospora cordifolia, an important medicinal plant,is a diploid $(2 n=22)$, deciduous climbing shrub belonging to family Menispermaceae. In ancient traditional Ayurvedic system of India, it is a constituent of several remediation used for various treatment such as general debility, dyspepsia and urinary diseases [10]. So keeping in view the advantage of silver nanoparticles synthesized from medicinal plants, our study is based on the synthesis of silver nanoparticles from T. cordifolia and checked its antibacterial activity against MDR strains of $P$. aeruginosa.

*Corresponding author: Jaya Parkash Yadav, Department of Genetics, M D University, Rohtak-124001, Haryana, India, Tel: 91-1262-393055; E-mail: yadav1964@rediffmail.com

Received February 17, 2014; Accepted March 23, 2014; Published March 30 2014

Citation: Singh K, Panghal M, Kadyan S, Chaudhary U, Yadav JP (2014) Antibacterial Activity of Synthesized Silver Nanoparticles from Tinospora cordifolia against Multi Drug Resistant Strains of Pseudomonas aeruginosa Isolated from Burn Patients. J Nanomed Nanotechnol 5: 192. doi:10.4172/2157-7439.1000192

Copyright: ( 2014 Singh K, et al. This is an open-access article distributed unde the terms of the Creative Commons Attribution License, which permits unrestricted use, distribution, and reproduction in any medium, provided the original author and source are credited. 
Citation: Singh K, Panghal M, Kadyan S, Chaudhary U, Yadav JP (2014) Antibacterial Activity of Synthesized Silver Nanoparticles from Tinospora cordifolia against Multi Drug Resistant Strains of Pseudomonas aeruginosa Isolated from Burn Patients. J Nanomed Nanotechnol 5: 192. doi:10.4172/2157-7439.1000192

\section{Material and Methods}

\section{Preparation of the plant extract}

The stem of Tinospora cordifolia was collected locally from Botanical Garden, M.D. University, Rohtak, Haryana, India. It was thoroughly washed in distilled water, cut into fine pieces. $15 \mathrm{~g}$ of fresh plant material was boiled into $100 \mathrm{ml}$ sterile distilled water and filtered through Whatman's No.1 filter paper. The extract was stored at $4^{\circ} \mathrm{C}$ for further experiments.

\section{Synthesis of silver nanoparticles from plant extract}

The aqueous solution of $1 \mathrm{mM}$ silver nitrate $\left(\mathrm{AgNO}_{3}\right)$ was prepared and used for the synthesis of silver nanoparticles. $15 \mathrm{ml}$ of plantextract was added into $200 \mathrm{ml}$ of aqueous solution of $1 \mathrm{mM}$ silver nitrate for reduction into $\mathrm{Ag}^{+}$ions and kept for $15-20$ minutes at $70-75^{\circ} \mathrm{C}$. This aqueous extract acts as reducing and stabilizing agent for $1 \mathrm{mM}$ of $\mathrm{AgNO}_{3}$. The prepared AgNPs were further characterized.

\section{Characterization techniques}

The techniques used for characterization were as follows:

UV-VIS spectroscopy: The Ag nanoparticles were characterized in a Shimadzu UV-VIS Spectrophotometer. The scanning range for the samples was $300-800 \mathrm{~nm}$. The double distilled water used as a blank reference.

Fourier Transform Infra-red Spectroscopy (FTIR): To remove any free biomass residue or compound that is not the capping ligand of the nanoparticles, after complete reduction, silver nanoparticles were concentrated by repeated centrifugation ( 3 times) of the reaction mixture at $15,000 \mathrm{rpm}$ for $20 \mathrm{~min}$. The supernatant was replaced by distilled water each time. Thereafter, the purified suspension was freeze dried to obtain dried powder. Finally, the dried nanoparticles were analysed by ALPHA FT-IR Spectrometer (from Bruker, Germany) for the detection of different functional groups by showing peaks from the region of $4000 \mathrm{~cm}^{-1}$ to $500 \mathrm{~cm}^{-1}$.

Transmission Electron Microscopy (TEM) and Energy Dispersive X-Ray Spectroscopy (EDX): The shape and size of AgNPs was determined by transmission electron microscopy. A drop (2 $\mu \mathrm{l})$ of water that dissolved synthesized nanoparticles was placed on a copper grid. The images were obtained with a Tecnai, Twin $200 \mathrm{KV}$ (FEI, Netherlands) at a bias voltage of $200 \mathrm{kV}$ used to analyse samples. The composition of the silver nanoparticles was determined using the EDX coupled to the TEM.

X- Ray Diffraction (XRD):The X-ray diffraction data were obtained by X-Pert Pro Diffractometer using step scan technique and with $\mathrm{Cu}-\mathrm{Ka}$ radiation $(1.500 \AA, 40 \mathrm{kV}, 30 \mathrm{~mA})$ in $\mathrm{h}-2 \mathrm{~h}$ configuration. The metal nanoparticles were coated on to the glass substrate and after drying the sample was analysed by X-ray diffractometer. The crystallite domain size was calculated using the Debye-Scherrer formula.

Multi drug resistant $P$. aeruginosa from clinical isolates: TwentyP. aeruginosaisolates were obtained from the various samples of burn patients receiving in Microbiology Department of Post Graduate Institute of Medical Sciences, Rohtak. The purity and identity of each isolate was confirmed in laboratory by standard microbiological methods [11-13]. The sources of the clinical isolates were urine, wounds, blood, and body fluids of burn cases. The ATCC 27853strain of $P$. Aeruginosa was served as positive control.

The 10 most cost-effective antibiotics routinely used to treat
$P$. aeruginosa infections were employed in the susceptibility test. The antibiotics included were amikacin, aztreonam, ceftizoxime, cefepime, gentamicin, imipenem, netilmicin, ofloxacin, piperacillin and tazobactum. For isolation of MDR strains, these antibiotics were used and susceptibility was checked by Kirby-Bauer disc method [14]. The strain which were resistant to 6 or 7 antibiotics was taken as MDR strain.

\section{Antibacterial assay of silver nanoparticles}

Preparation of test samples: 4 Test samples of the AgNPs were prepared in DMSO (Dimethyl Sulfoxide). The concentration ranges from $12.5-200 \mu \mathrm{g} / \mathrm{ml}$ i.e. $12.5,25,50,100$, and $200 \mu \mathrm{g} / \mathrm{ml}$.

Antimicrobial bioassay: The antimicrobial activities were determined by modified agar well diffusion assay [15]. Under aseptic conditions, in to the Bio safety chamber, $20 \mathrm{ml}$ of MHA medium was dispensed in to pre-sterilized petridishes. Once the media solidifies it was then inoculated with micro-organism suspended in peptone water The media was then punched with $6 \mathrm{~mm}$ diameter hole and filled with different dilutions (varying from 2.5 to $20 \mu \mathrm{l}$ ) of AgNPs extract from stock of $20 \mathrm{mg} / \mathrm{ml}$. Streptomycin discs for bacteria $(10 \mu \mathrm{g} / \mathrm{disc})$ were used as positive controls and DMSO was used as a negative control. Finally, the petridishes were incubated for 24 hours at $37^{\circ} \mathrm{C}$. The diameter of zone of inhibition as indicated by clear area which was devoid of growth of microbes was measured. Each experiment was done in triplicate.

\section{Minimum inhibitory concentration method (MIC)}

This method is based on a micro broth dilution method in 96 multi-well microtitre plates with slight modifications [16]. Qualitative experimentation by resazurin indication solution prepared by dissolving a $270 \mathrm{mg}$ tablet in $40 \mathrm{ml}$ of sterile distilled water. Indicator resazurin of purple color reduced in the presence of living bacteria. Color change from purple to pink or to colorless. In the absence of living bacteria the color of the indicator were remain purple. The lowest conc. at which color change occurred was taken as MIC.

\section{Result and Discussion}

\section{Synthesis of AgNPs}

The green synthesis of silver nanoparticles through plant extracts were carried out. On mixing the plant extract of T. cordifolia with silver nitrate solution $(1 \mathrm{mM})$, a change in the colour from pale yellow to dark brown was observed (Figure 1). Similar results were also reported by many researchers [17-19]. The brown colour confirms that it was due to the reduction of $\mathrm{Ag}^{+}$which indicates the formation of $\mathrm{Ag}$ nanoparticles.

\section{Characterization of Ag Nanoparticles}

UV-VIS spectral analysis: In our results peak specific for the synthesis of silver nanoparticles was obtained at $420-425 \mathrm{~nm}$ by UVVisible spectroscope in the form of a sharp peak (Figure 2), which was specific for the synthesis of AgNPs. It is well known that colloidal silver nanoparticles exhibit absorption at the wavelength from 390 to 420 $\mathrm{nm}$ due to Mie scattering [20]. Hence, the band at $420-430 \mathrm{~nm}$ can be attributed to the property of Mie scattering. This may not include the protecting agent, because the Mie scattering responds only to the silver metal [21].

FTIR analysis: The aim of IR spectroscopic analysis is to determine chemical functional groups in the sample. The amide linkages between amino acid residues in polypeptides and proteins give rise to wellknown signatures in the infra-red region of the electromagnetic 
Citation: Singh K, Panghal M, Kadyan S, Chaudhary U, Yadav JP (2014) Antibacterial Activity of Synthesized Silver Nanoparticles from Tinospora cordifolia against Multi Drug Resistant Strains of Pseudomonas aeruginosa Isolated from Burn Patients. J Nanomed Nanotechnol 5: 192. doi:10.4172/2157-7439.1000192

Page 3 of 6

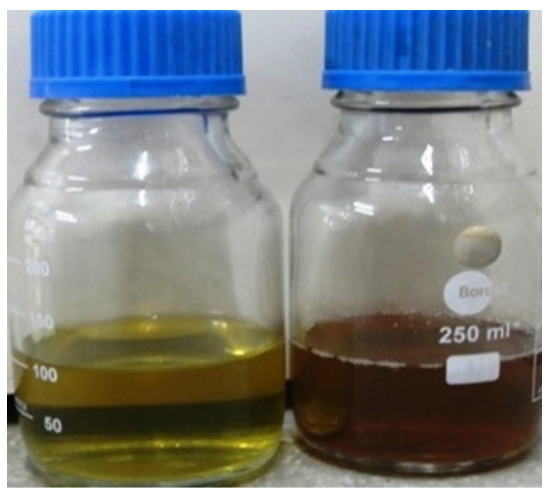

Figure 1: Picture shows the colour change (a) Before (b) After the reduction of $\mathrm{Ag}+$ into AgNPs of T. cordifolia.

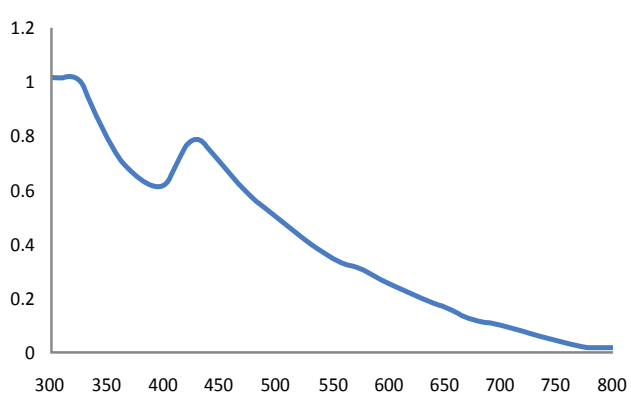

Figure 2: UV-VIS absorption spectra of AgNPs of $T$. cordifolia at a range of $300-800 \mathrm{~nm}$.

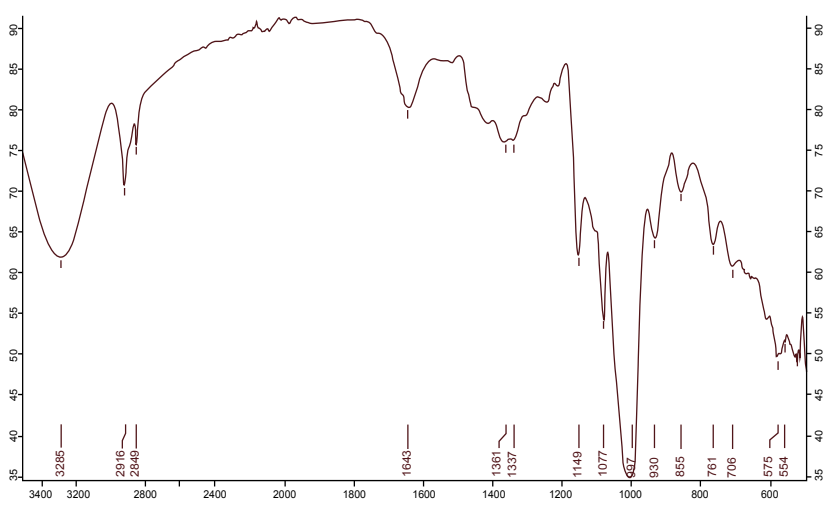

Figure 3: FTIR spectra of vacuum dried powder of synthesized AgNPs of T. cordifolia from stem.

\section{spectrum.}

Different functional groups absorb characteristic frequencies of IR radiation. Thus, IR spectroscope is an important and popular tool for structural elucidation and compound identification. Our observation confirms the presence of such compounds in the sample which coat covering the silver nanoparticles known as capping agents. FTIR analysis of AgNPs from stem of T. cordifolia has been shown in Figure 3. FTIR showed the presence of bands due to $\mathrm{O}-\mathrm{H}$ stretching due to $\left(3,285 \mathrm{~cm}^{-1}\right)$ vibration of the alcoholic compounds, aldehydic $\mathrm{C}-\mathrm{H}$ stretch $\left(2,916\right.$ and $\left.2,849 \mathrm{~cm}^{-1}\right), \mathrm{C}-\mathrm{O}$ stretch $\left(1,643 \mathrm{~cm}^{-1}\right)$ arises from carbonyl group, $\mathrm{N}-\mathrm{O}, \mathrm{C}-\mathrm{C}\left(1,361\right.$ and $\left.1,337 \mathrm{~cm}^{-1}\right)$ and $\mathrm{C}-\mathrm{O}$ stretch (dialkyl) $\left(1,149 \mathrm{~cm}^{-1}\right), \mathrm{C}-\mathrm{N}\left(1,077 \mathrm{~cm}^{-1}\right), \mathrm{C}-\mathrm{H}\left(761 \mathrm{~cm}^{-1}\right)$. Similar kind of results has been showed by many researchers too [18,19] in FTIR analysis of AgNPs of T. cordifolia. This study gives the evidence of formation and stabilization of silver nanoparticles in the aqueous medium by using biological molecules.

TEM analysis: TEM confirmed the development of silver nanostructures and gave clear image of silver nanoparticles. We observed that the shapewas spherical and sizeof silver nanoparticles was $36 \pm 9 \mathrm{~nm}$ synthesized from T. cordifolia (Figure 4).

EDX analysis: EDX characterization has shown absorption of strong silver signal along with other elements, which may be originate from the biomolecules that are bound to the surface of nanosilver particles.From EDX spectra, shown in Figure 5, it is clear that silver nanoparticles reduced by $T$. cordifolia.

XRD analysis: The crystalline nature of the silver nanoparticles was carried out by XRD. The XRD pattern was ranging from five strong peaks were observed at 10.7, 11.15, 14.5, 7.03, 9.3, 11.2, 10.5, 23.8 and 14.3that corresponds to the planes, which are indexed to the face

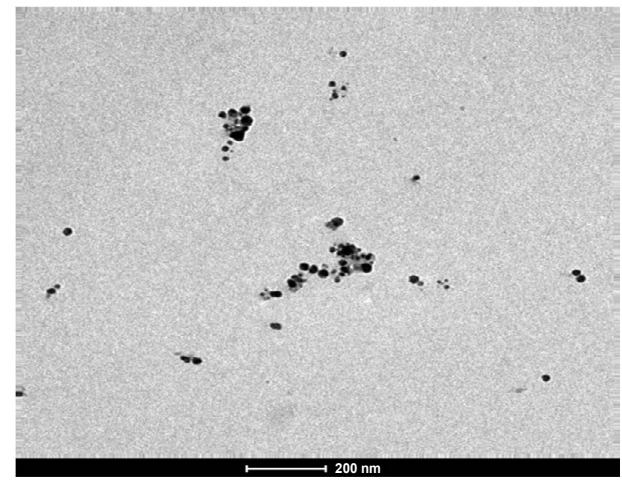

Figure 4: Image of transmission electron microscopic observation of synthesized silver Nanoparticles of $T$. cordifolia from stem.

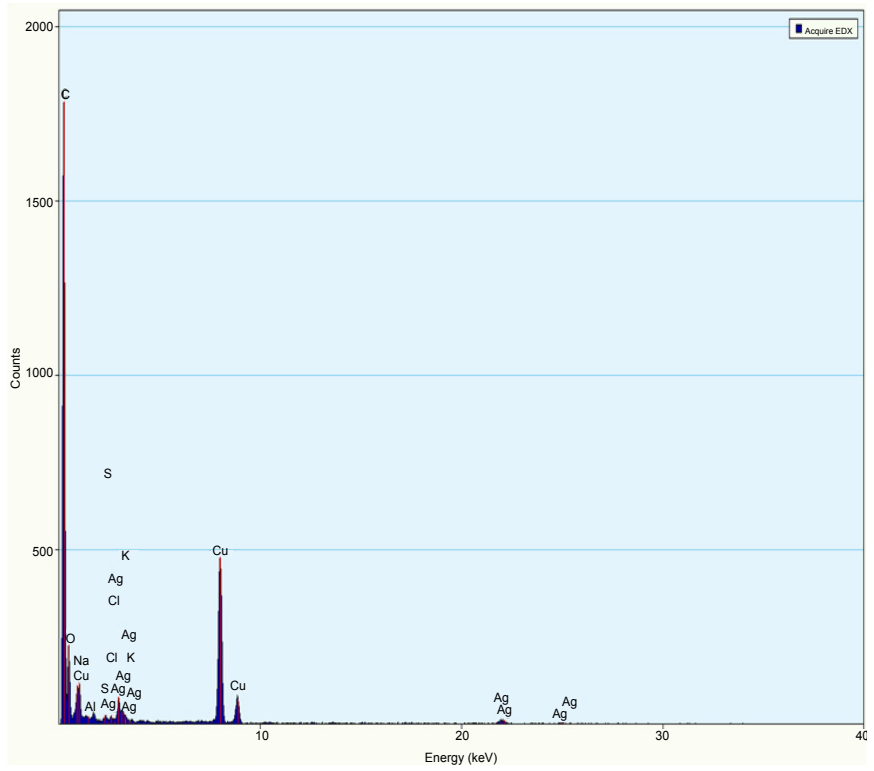

Figure 5: Image of EDX of synthesized silver Nanoparticles of $T$. cordifolia from stem. 
Citation: Singh K, Panghal M, Kadyan S, Chaudhary U, Yadav JP (2014) Antibacterial Activity of Synthesized Silver Nanoparticles from Tinospora cordifolia against Multi Drug Resistant Strains of Pseudomonas aeruginosa Isolated from Burn Patients. J Nanomed Nanotechnol 5: 192. doi:10.4172/2157-7439.1000192

Page 4 of 6

\begin{tabular}{|c|c|c|c|c|c|c|}
\hline S.No & 2-theta(deg) & D (ang.) & $\begin{array}{c}\text { FWHM } \\
\text { (deg) }\end{array}$ & Int. I (cps deg) & $\begin{array}{c}\text { Int. } \\
\text { W(deg) }\end{array}$ & Size(nm) \\
\hline 1 & 28.006 & 3.183 & 0.796 & 189 & 0.949 & 10.7 \\
\hline 2 & 32.237 & 2.774 & 0.774 & 387.58 & 0.929 & 11.1 \\
\hline 3 & 38.191 & 2.354 & 0.601 & 856.65 & 0.979 & 14.5 \\
\hline 4 & 44.347 & 2.040 & 1.273 & 220.52 & 1.541 & 7.03 \\
\hline 5 & 46.209 & 1.962 & 0.963 & 211.25 & 1.113 & 9.3 \\
\hline 6 & 54.771 & 1.674 & 0.829 & 65.73 & 1.108 & 11.2 \\
\hline 7 & 57.517 & 1.601 & 0.893 & 73.6 & 1.270 & 10.5 \\
\hline 8 & 64.578 & 1.441 & 0.411 & 175.65 & 0.766 & 23.8 \\
\hline 9 & 77.352 & 1.232 & 0.738 & 209.36 & 1.083 & 14.3 \\
\hline
\end{tabular}

Table1: Measurement of the size of AgNPs of Tinospora cordifolia by using DebyeScherrer's equation.

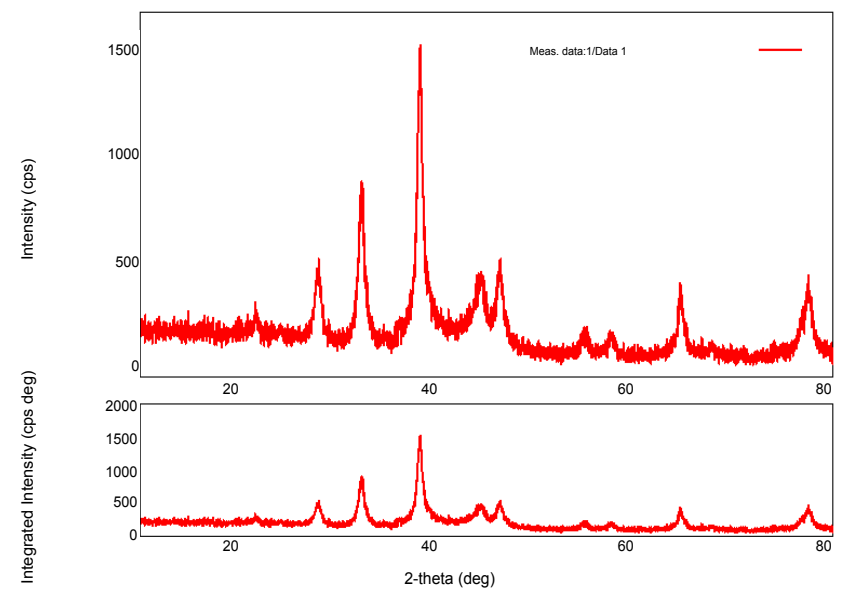

Figure 6: XRD diffraction pattern of synthesized AgNPs of T. cordifolia.

centred cubic structures of silver nanoparticles. The synthesis of silver nanoparticles with sharp bands of Bragg peaks, and this might be due to the stabilization of the synthesized nanoparticles by the various reducing agents of the T.cordifolia, and thus provides the crystallization nature of the silver nanoparticles [22]. The mean size of silver nanoparticles was calculated using the Debye-Scherrer's equation. An average size of the silver nanoparticles synthesized by T. cordifolia was $12.49 \mathrm{~nm}$ with size ranging from $9.3 \mathrm{~nm}$ and $23.8 \mathrm{~nm}$ (Table 1). XRD diffraction pattern of synthesized AgNPs of T. cordifolia was shown in Figure 6.

\section{Antibacterial activity of AgNPs against MDR strains of P.aeruginosa}

The inhibitory action of silver compounds and silver ions had been historically recognized and applied as a useful therapeutic agent for preventing wound infections. The inhibitory action of silver on bacterial cells is related to the strong interaction of silver with thiol groups present in key respiratory enzymes in bacteria [23]. Whereas, Nano crystalline silver shows the most effective inhibitory action with a rapid inhibition rate [24]. In the present study T. cordifolia was taken for synthesis of AgNPs because of its medicinal values. Various studies have been done by many researchers which confirm that $T$. cordifolia was found to be good antibacterial agentagainst pathogenic and non-pathogenic organisms [25-28]. The antibacterial effects of the bio-synthesized silver nanoparticles from T. cordifolia were also successfully investigated $[19,29]$. Also there are various reports which have been providing the evidences that silver nanoparticles were used as powerful tool against multidrug-resistant bacteria [30,31]. Kora and Arunachalam [32] showed that silver nanoparticles synthesized by UV photo-reduction method are showing promising antibacterial activity on $P$. aeruginosa at much lower concentrations. As these above reports suggests that both silver nanoparticles and T. cordifolia plant extract have shown good amount of antibacterial activity. Durairaj et al.[33] studied the antibacterial activity of purchased AgNPs (size 20-30nm) against 10 isolates of $P$. aeruginos a comprising of $5 \mathrm{MDR}$ strains with an inhibition zone of $11 \mathrm{~mm}$ observed with $10 \mu \mathrm{g}$ dose of the nanoparticles. The nanoparticles exhibited MIC of50 $\mu \mathrm{g} / \mathrm{ml}$ when added at the lag phase and the sub inhibitoryconcentration was measured as $100 \mu \mathrm{g} /$ ml. In our experiment, when we compared the antibacterial activity of AgNPs and plant extract, it was found that silver AgNPs have shown more antibacterial activity than plant extracts. Our results clearly shows that the conventional plant extract showing some antibacterial activity but not much activity as AgNPs does against these MDR bacterial strains (Table 1), even taken in amount10 times more than AgNPs (Figure S1). It clearly indicates that these green AgNPs have shown considerable amount of activity than that of plant extract. Antibacterial activity of AgNPs significantly increases by more than $12-15 \%$ at very lower concentration i.e. almost 18 out of 20 strains have shown zone of inhibition comes at concentration of $4 \mathrm{mg} / \mathrm{ml}$ in case of plant extract whilein case of AgNPs $200 \mu \mathrm{g} / \mathrm{ml}$ is the highest concentration we have used. Therefore we further proceeds only with the results of antibacterial activity of AgNPs.

Also if we use synthetic or purchased AgNPs then there may be a problem due to chemical agents used. So we synthesized AgNPs by plant extract of $T$. cordifolia which potentially eliminate the problem of chemical agents that may arise if we used any synthetic or chemically synthesized AgNPs, thus making nanoparticles biocompatible with the eco-friendly approach. The antibacterial efficacy of synthesized AgNPs enhances because the use of silver and T. cordifolia, as silver reduced in nano form which increases its surface area, thus make AgNPs more reactive and T. cordifolia enhances the therapeutic efficacy of AgNPs due to its good antibacterial efficacy. Therefore, in our study, AgNPs prepared by T. cordifolia were used for the development of antibacterial agents against MDR strains of $P$. aeruginosa.

We have checked the antibacterial activity of AgNPs by agar well diffusion method against twenty MDR strains of $P$. aeruginosa from burn patients. In our experiment, biosynthesized AgNPs showed excellent antibacterial activity against MDR strains of $P$. aeruginosa (Figure 7). Our results showed that AgNPs synthesized from T. cordifolia possess discrete antibacterial activity at different concentrations of $6.25-200$ $\mu \mathrm{g} / \mathrm{mL}$ (Table 2). The zone of inhibition ranges from $10 \pm 0.58$ to 21

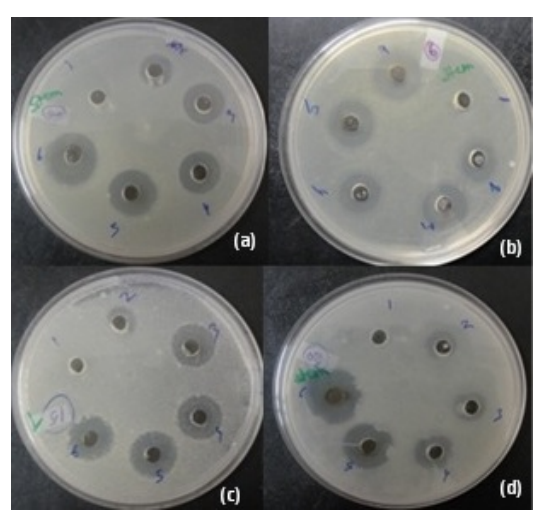

Figure 7: Showing antibacterial activity of AgNPs of $T$. cordifolia against MDR strains of $P$. aeruginosa from burn patients (a) MDR strain 2 (b) MDR strain 6 (c) MDR strain 15 (d) MDR strain 20. 
Citation: Singh K, Panghal M, Kadyan S, Chaudhary U, Yadav JP (2014) Antibacterial Activity of Synthesized Silver Nanoparticles from Tinospora cordifolia against Multi Drug Resistant Strains of Pseudomonas aeruginosa Isolated from Burn Patients. J Nanomed Nanotechnol 5: 192. doi:10.4172/2157-7439.1000192

Page 5 of 6

\begin{tabular}{|c|c|c|c|c|c|c|}
\hline \multirow{2}{*}{$\begin{array}{l}P . \text { aeruginosa } \\
\text { MDR strains }\end{array}$} & \multicolumn{5}{|c|}{ Zone of Inhibition (in mm) at different AgNPs conc. } & \multirow{2}{*}{$\begin{array}{c}\begin{array}{c}\text { +ve control } \\
\text { (Streptomycin) }\end{array} \\
10 \mu \mathrm{g}\end{array}$} \\
\hline & $12.5 \mu \mathrm{g} / \mathrm{ml}$ & $25 \mu \mathrm{g} / \mathrm{ml}$ & $50 \mu \mathrm{g} / \mathrm{ml}$ & $100 \mu \mathrm{g} / \mathrm{ml}$ & $200 \mu \mathrm{g} / \mathrm{ml}$ & \\
\hline 1 & - & - & $11 \pm 0.58$ & $12 \pm 2.30$ & $17 \pm 0.58$ & $12 \pm 0.58$ \\
\hline 2 & $10 \pm 0.58$ & $11 \pm 1$ & $15 \pm 1$ & $16 \pm 0.58$ & $19 \pm 0.29$ & $13 \pm 0.14$ \\
\hline 3 & $10 \pm 0.58$ & $11 \pm 0.46$ & $11 \pm 0.34$ & $13 \pm 0.17$ & $14 \pm 0.5$ & $12 \pm 1$ \\
\hline 4 & - & - & - & - & $10 \pm 1$ & $15 \pm 0.77$ \\
\hline 5 & - & $10 \pm 0.58$ & $12 \pm .06$ & $13 \pm 0.11$ & $16 \pm 0.29$ & $14 \pm 0.33$ \\
\hline 6 & $11 \pm 0.55$ & $13 \pm 0.46$ & $17 \pm 0.34$ & $18 \pm 0.55$ & $20 \pm 0.58$ & $12 \pm 0.64$ \\
\hline 7 & - & - & - & - & $10 \pm 0.46$ & $15 \pm 1$ \\
\hline 8 & - & - & - & - & $12 \pm 0.5$ & $16 \pm 1$ \\
\hline 9 & $10 \pm 0.58$ & $10 \pm 1$ & $11 \pm 0.34$ & $12 \pm 0.29$ & $13 \pm 0.58$ & $11 \pm 0.41$ \\
\hline 10 & - & $10 \pm 0.55$ & $11 \pm 0.58$ & $14 \pm 0.50$ & $15 \pm 0.46$ & $13 \pm 0.28$ \\
\hline 11 & - & - & - & - & $15 \pm 0.29$ & $14 \pm 1$ \\
\hline 12 & - & $10 \pm 0.58$ & $10 \pm 1$ & $13 \pm 0.46$ & $14 \pm 0.58$ & $13 \pm 1$ \\
\hline 13 & - & - & - & - & $12 \pm 0.58$ & $15 \pm 1$ \\
\hline 14 & - & - & - & - & $10 \pm 1$ & $16 \pm 0.48$ \\
\hline 15 & - & $13 \pm 1$ & $17 \pm 0.58$ & $17 \pm 0.33$ & $18 \pm 0.58$ & $12 \pm 0.33$ \\
\hline 16 & - & $13 \pm 1$ & $12 \pm 0.58$ & $11 \pm 0.33$ & $10 \pm 0.58$ & $12 \pm 0.33$ \\
\hline 17 & $11 \pm 0.46$ & $13 \pm 0.58$ & $15 \pm 0.58$ & $16 \pm 41$ & $14 \pm 0.52$ & $11 \pm 0.28$ \\
\hline 18 & - & - & $10 \pm 0.58$ & $11 \pm 1$ & $12 \pm 0.58$ & $11 \pm 1$ \\
\hline 19 & $11 \pm 0.46$ & $13 \pm 0.58$ & $13 \pm 0.58$ & $14 \pm 1$ & $14 \pm 0.52$ & $12 \pm 0.58$ \\
\hline 20 & $10 \pm 1$ & $11 \pm 0.33$ & $13 \pm 0.58$ & $17 \pm 0.58$ & $21 \pm 0.25$ & $10 \pm 1$ \\
\hline
\end{tabular}

Table 2: Zone of inhibition of AgNPs of T. cordifolia at different concentration against 20 MDR strains of Pseudomonas aeruginosa isolated from burn patients.

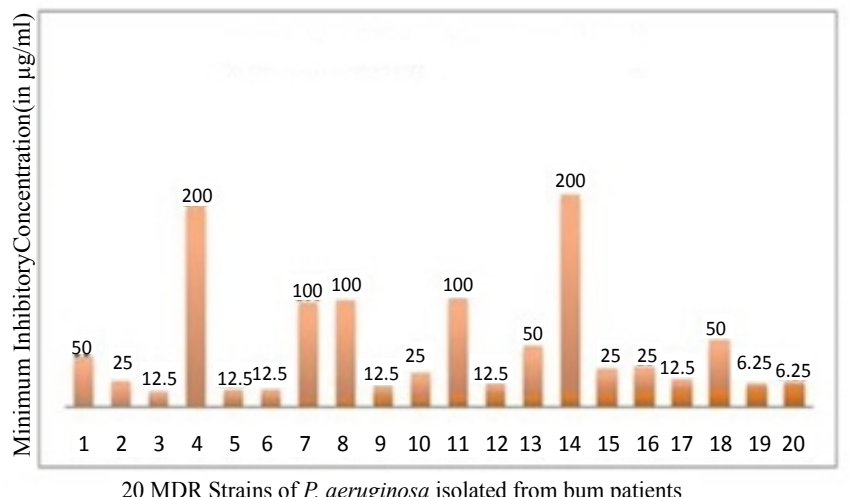

Figure 8: Minimum Inhibitory Concentration (MIC) of AgNPs of $T$. cordifolia against twenty MDR Strains of $P$. aeruginosa from burn patients

$\pm 0.25 \mathrm{~mm}$. The highest zone of inhibition was $21 \pm 0.25 \mathrm{~mm}$, found against MDR strain 20. Further MIC was calculated by resazurin based microtitre well plate method. The MIC of AgNPs from stem of T.cordifolia varies $6.25-100 \mu \mathrm{g} / \mathrm{ml}$ have been shown in Figure 8, was found to be strongly inhibitory against MDR strains. MDR strain 19 and 20 showed the lowest value of MIC $6.25 \mu \mathrm{g} / \mathrm{mL}$ while MDRstrain 4 and 14 showed the highest value MIC $200 \mu \mathrm{g} / \mathrm{mL}$. The antibacterial activity of AgNPs have depicted that as we increases the conc. of AgNPs the antibacterial activity against MDR strains of $P$. aeruginosa increased parallely. The study revealed that high antibacterial activity was found against tested strains of $P$. aeruginosa at very low concentration of AgNPs (in $\mu \mathrm{g} / \mathrm{ml}$ ). Our resultsalso correlates with the work previously done by some researchers which studied the antibacterial effect of silver nanoparticles against Multi Drug Resistant strains of $P$. aeruginosa [6,33]. Afreen et al. [6] synthesized AgNPs from a fungus, Rhizopussto lonifer and checked its efficacy against two MDR strains isolated from burn cases from hospitals at Gulbarga region, Karnataka, India. Whereas, our study emphasises thatuse of plant extract reduces the cost of micro-organism isolation and also reducing the complicated process of maintaining the cell culture over nanoparticles synthesis by microorganisms. Durairaj et al. [33]studied the antibacterial activity of purchased AgNPs (size 20-30 nm) against 10 isolates of $P$. aeruginosa comprising of 5 MDR strains have shown significant antibacterial effect.

Moreover, when antibacterial activity of AgNPs synthesized from that plant extract was compared with the plant extract alone, it clearly shows that the conventional plant extract showing not much activity as AgNPs does against these MDR bacterial strains, even taken in amount10 times more than AgNPs (Figure S1). It clearly indicates that these green AgNPs have shown considerable amount of activity than that of plant extract. Antibacterial activity of AgNPs significantly increases by more than $12-15 \%$ i.e. zone of inhibition comes at concentration of $\mathrm{mg} / \mathrm{ml}$ in case of plant extract and $\mu \mathrm{g} / \mathrm{ml}$ in case of AgNPs. Therefore we further proceeds only with the results of antibacterial activity of AgNPs.Our method of synthesis of AgNPs was a simple, cost effective and eco-friendly method. The synthesized AgNPs of T. cordifolia from 
Citation: Singh K, Panghal M, Kadyan S, Chaudhary U, Yadav JP (2014) Antibacterial Activity of Synthesized Silver Nanoparticles from Tinospora cordifolia against Multi Drug Resistant Strains of Pseudomonas aeruginosa Isolated from Burn Patients. J Nanomed Nanotechnol 5: 192. doi:10.4172/2157-7439.1000192

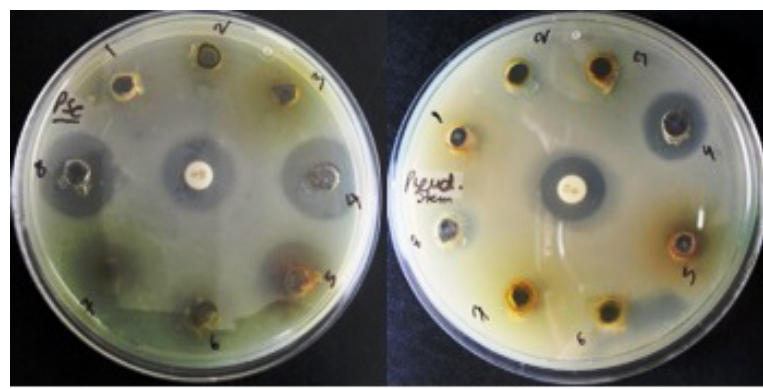

Figure s1: Showing comparison of antibacterial activity of AgNPs of $T$ cordifolia with conventional plant extracts of $T$. cordifolia.

stem showed remarkable antibacterial activity against all the strains which makes them a potent source of antibacterial agent.

\section{Conclusions}

From the present study we conclude that even at very small concentration (in $\mu \mathrm{g} / \mathrm{ml}$ ) AgNPs from stem of T. cordifolia possess very good antibacterial activity which makes them a potent source of antibacterial agent against MDR strains of $P$. aeruginosa. Also, green synthesis of AgNPs can potentially eliminate the problem of chemical agents that may have adverse effects, thus making nanoparticles more compatible with the eco-friendly approach. Moreover the synthesized AgNPs enhance the therapeutic efficacy and strengthen the medicinal values of T. cordifolia. Hence, our results are promising and prove to be an important step in this direction as it decreases the burden of multidrug resistance in burn patients.

\section{Acknowledgement}

The authors are thankful to National Medicinal Plant Board (Grant no.\& DateZ.18017/187/CSS/R\&D/HR-01/2011-12-NMPB/24/11/2011), New Delhi for the award of Major Research Project grant

\section{References}

1. Church D, Elsayed S, Reid O, Winston B, Lindsay R (2006) Burn wound infections. Clin Microbiol Rev 19: 403-434.

2. Pruitt BA Jr, McManus AT, Kim SH, Goodwin CW (1998) Burn wound infections: current status. World J Surg 22: 135-145.

3. Estahbanati HK, Kashani PP, Ghanaatpisheh F (2002) Frequency of Pseudomonas aeruginosa serotypes in burn wound infections and their resistance to antibiotics. Burns 28: 340-348.

4. Jamasbi RJ, Proudfoot EM (2008) Phenotypic and genotypic characteristics of clinical isolates of Pseudomonas aeruginosa: Rate of occurrence and distribution of different serotypes, antimicrobial susceptibility profiles, and molecular typing. Lab Med 39: 155-161.

5. Porras-Gomez M, Vega-Baudrit, Nunez-Corrales S (2012) Overview of Multidrug-Resistant Pseudomonas aeruginosa and novel therapeutic approaches. Journal of Biomaterials and Nanobiotechnology 3: 519-527.

6. Afreen, Rathod V, Ranganath E (2011) Synthesis of monodispersed silver nanoparticles by Rhizopus stolonifer and its antibacterial activity against MDR strains of Pseudomonas aeruginosa from burnt patients. International Journal of Environmental Sciences 1: 1583-1592.

7. Mudshinge SR, Deore AB, Patil S, Bhalgat CM (2011) Nanoparticles: Emerging carriers for drug delivery. Saudi Pharm J 19: 129-141.

8. Huang X, Jain PK, El-Sayed IH, El-Sayed MA (2007) Gold nanoparticles: interesting optical properties and recent applications in cancer diagnostics and therapy. Nanomedicine (Lond) 2: 681-693.

9. Salam HA, Rajiv P, Kamaraj M, Jagadeeswaran P, Gunalan S, et al. (2012) Plants: Green route for nanoparticle synthesis. I Res J Biological Sci 1: 85-90.

10. Ahmad SM, Hoot SB, Qazi PH, Verma V (2009) Phylogenetic patterns and genetic diversity of Indian Tinospora species based on chloroplast sequence data and cytochrome P450 polymorphisms. Plant Systematics and Evolution 281: 87-96.
11. Ryan KJ (2004) Normal Microbial flora. Medical Microbiology. Fourth edition. Edited by Sherris JC, RyanKJ, Ray GC. McGraw Hill, USA.

12. Hawkey P, Lewis DA (2004) Medical Bacteriology: A Practical Approach. Oxford University Press, New York, USA.

13. Pawar VB, Dutta D (2006) A procedure manual for routine diagnostic test Diagnostics Bacteriology. Edited by Mukherjee KL. Tata McGraw-Hill Publishing Company Limited, New Delhi 2: 554-562.

14. Bauer AW, Kirby WM, Sherris JC, Turck M (1966) Antibiotic susceptibility testing by a standardized single disk method. Am J Clin Pathol 45: 493-496.

15. Perez C, Pauli M, Bezevque P (1990) An antibiotic assay by agar well diffusion method. Acta Biologiae Medicine Experimentalis 15: 113-115.

16. Sarker SD, Nahar L, Kumarasamy Y (2007) Microtitre plate-based antibacterial assay incorporating resazurin as an indicator of cell growth, and its application in the in vitro antibacterial screening of phytochemicals. Methods 42: 321-324.

17. Krishnaraj C, Jagan EG, Rajasekar S, Selvakumar P, Kalaichelvan PT, et al. (2010) Synthesis of silver nanoparticles using Acalypha indica leaf extracts and its antibacterial activity against water borne pathogens. Colloids Surf B Biointerfaces 76: 50-56.

18. Jayaseelan C, Rahuman AA, Rajakumar G, Vishnu Kirthi A, Santhoshkumar T, et al. (2011) Synthesis of pediculocidal and larvicidal silver nanoparticles by leaf extract from heartleaf moonseed plant, Tinospora cordifolia Miers. Parasitol Res 109: 185-194.

19. Anuj SA, Ishnava KB (2013) Plant mediated synthesis of silver nanoparticles by using dried stem powder of Tinospora cordifolia, its antibacterial activity and comparison with antibiotics. Int J Pharm Bio Sci 4: 849-863.

20. Kleemann W (1993) Random-field induced antiferromagnetic, ferromagnetic and structural domain states. International Journal of Modern Physics B 7 : 2469-2507.

21. Aoki K, Chen J, Yang N, Nagasawa H (2003) Charge transfer reactions of silver stearate-coated nanoparticles in suspensions. Langmuir 19: 9904-9909.

22. Nabikhan A, Kandasamy K, Raj A, Alikunhi NM (2010) Synthesis of antimicrobial silver nanoparticles by callus and leaf extracts from saltmarsh plant, Sesuvium portulacastrum L. Colloids Surf B Biointerfaces 79: 488-493.

23. Gordon O, Vig Slenters T, Brunetto PS, Villaruz AE, Sturdevant DE, et al (2010) Silver coordination polymers for prevention of implant infection: thio interaction, impact on respiratory chain enzymes, and hydroxyl radical induction. Antimicrob Agents Chemother 54: 4208-4218.

24. Wright JB, Lam K, Burrell RE (1998) Wound management in an era of increasing bacterial antibiotic resistance: a role for topical silver treatment. Am J Infect Control 26: 572-577.

25. Jeyachandran R, Xavier TF, Anand SP (2003) antibacterial activity of stem extracts of Tinospora cordifolia (Willd) Hook. $f$ \& Thomson. Anc Sci Life 23 40-43.

26. Duraipandiyan V, Ignacimuthu S, Balakrishna K, Al-Harbi NA (2012) Antimicrobial activity of Tinospora cordifolia: an ethnomedicinal plant. Asian J Trad Med 7: 1-7.

27. Uddin MH, Hossain MA, Kawsar MH (2011) Antimicrobial and cytotoxic activities of Tinospora cordifolia (Fam: Menispermaceae). IJPSR 2: 656-658.

28. Rajathi K, Vijaya Raj D, Anarkal J, Sridhar S (2012) Green Synthesis, characterization and in-vitro antibacterial activity of silver nanoparticles by using Tinospora cordifolia leaf extract. International Journal of Green Chemistry and Bioprocess 2: 15-19.

29. Shanthi V, Nelson R (2013) Antibacterial activity of Tinospora cordifolia (Willd) Hook.F.Thoms on urinary tract pathogens. Int J Curr Microbiol App Sci 2: 190 194.

30. Lara HH, Ayala-Nunez NV, Turrent LCl, Padilla CR (2010) Bactericidal effect of silver nanoparticles against multidrug-resistant bacteria. World Journal of Microbiology and Biotechnology 26: 615-621.

31. Rai MK, Deshmukh SD, Ingle AP, Gade AK (2012) Silver nanoparticles: the powerful nanoweapon against multidrug-resistant bacteria. J Appl Microbiol 112: 841-852.

32. Kora AJ, Arunachalam J (2011) Assessment of antibacterial activity of silver nanoparticles on Pseudomonas aeruginosa and its mechanism of action. World Journal of Microbiology and Biotechnology 27: 1209-1216.

33. Durairaj R, Amirulhusni AN, Palanisamy NK, Mohd-Zain Z, Ping LJ (2012) Antibacterial effect of silver nanoparticles on multi drug resistant $P$ seudomonas aeruginosa. World Academy of Science, Engineering and Technology 6: 210213. 